raised, ejelids closed, and all the usual signs of insensibility to pain. The circular incision was now made through the skin, and he cried out most lustily, and continuel doing so through the whole stage of the operation. After it was all over he stated he felt the first cut, and also the bone sawed, but he was in a dream, and smoking a pipe, which some one tried to take from him.

I can only view this case as a failure, and I think it right alike to report all, whether failures or not. The other cases were decidedly successful. I may otate in the abore operation the mouth-piece did not nicely fit the mouth, and he appeared to hare inhaled fresh air by its side.

Albion House, Cheltenham, February, 1847.

\section{REMOVAL OF THE GREAT TOE AND PART} OF THE METATARSAL BONE, UNDER THE INFLUENCE OF ETHER.

\section{By T. HzRBprt Barxpr, M.B., M.R.C.S.}

Emma Rawlins, aged 23, of Cople, near Bedford, had bren labouring under strumous disease of the great toe, involving the phalanges and part of the metatarsal bone, during the last five years, and was anxious to have the diseased parts removed by operation.

Desirons of giving her the benefit of inhaling the vapour of æther, I procured the apparatus constructed under the directions of Dr. Boott and Mr. James Robinson, and sold by Mr. Hooper, of Pall Mall, London, and yesterday removed the parts in the following manner, with the kind assistance of Mr. Hurst, and in the presence of Messrs. C. W. Hyne, W. Bailey, Anthony, Bireh, Cox, and Ravenscroft:-

Having succeeded in about four minutes in getting her thorovighly under the influence of the rapour, a flap of good size was made, with a scalpel on the inner side of the foot, the metalarsal bone being laid bare beyond the extent of the disease. A strong bistoury was then passed through the space between the metatarsal bones of the first and second toe, in close contact with the former, and brought out anteriorly; the flexor and extensor tendons were divided, and the metatarsal bone nipped through with Liston's forceps. The exposed surfaces were sponged, and the flap secured by three points of interrupted suture.

During the operation, which lasted but a short time, the supply of vapour was cut of by means of the stopcock; she did not in the least shrink from the knife, nor did she manifest in any way the slightest sign or expression of pain. On regaining her consciousness, she inquired when the operation would commence, and on being told that it was all over, stated that she had been asleep and dreaming.

The testimony of so many operalors has already been recorded of the efficacy of the inhaled wther, in com: pletely deadening the sensibility of the system, during severe and protracted operations, that there cannot be a doubt that this is one of the grealest discoveries of the age, productive as has been that age of great discoveries.
I thought it desirable that my patient should be pre. viously tutored in the process of inhaling, and for that purpose induced her to inhale the æther the day before the operation, which she did, to the entire satisfaction of both of us. This appears to be a matter of some importance, and likely to contribute to the success of the process, for there are several precautions which are better thus explained beforehand, and the patient will be less likely to be affected by timidity at the time of the operation.

The points which appear to require particular attention are :-

1. To tutor the patient beforehand in the process of inhaling.

2. To give charge of the inhaling apparatus to a trustworthy assistant, who should keep the mouth-pad in firm contact with the lips.

3. To allow two or three inspirations to be made before removing the small stopper, and applying the nasal spring, otherwise the fall volume of the vapour. will be likely to excite coughing and a sense of suffocation.

4. To cut off the supply of vapour for a time, by turning the stop-cock and removing the nasal nipper, when deep insensibility has been produced.

The morbid effects of the inhalation of æther have yet to be made out, and good service will be rendered to the profession and humanity, by any one who will investigate the precise effects of this powerful agent, when administered in cases complicated with pulmonary, cardiac, or cerebral mischief. Some affections of the heart, and a strong predisposition to cerebral disease, will probably be found to be the morbid conditions more particularly contra-indicating its employment.

Bedford, February 16, 1847.

\section{REMOVAL OF THE NAIL FROM THE GREAT} TOE, UNDER THE INFLUENCE OF THE VAPOUR OF SULPHURIC ETHEIS.

On Monday, January 18th, Mr. Rudall, surgeon, of Sheeprash, North Deron, in the presence of J. G. Maxwell, Esq., performed the operation of removal of the great toe nail with part of the toe, on the person of an athletic farm-labourer, aged 22 years, the patient being put under the influence of the mther vapour. The result in the most satisfactory manner, confirmed all that has been reported of this extraordinary means of subduing pain in the performance of surgical operations. The vapour was administered by means of an apparatus extemporaneously constructed, and consisted of a large.sized bullock's bladder, to which was con nected a tube of half an inch in calibre, and two and a half inches in length, this was attached to a bulb capable of containing about eight ounces of fluid; continued from this was a tube seren inches in length, and a quarter of an inch in calibre. The other (six drachms,) being put into the bladder, which was afterwards inflated, and the tube being introduced into the patient's mouth, the inhalation was commenced. In rather less than one minute perfect insensibility was produced, a gentle tremulous motion of the lips, 